\title{
Combining MODIS, AVHRR and in situ data for evapotranspiration estimation over heterogeneous landscape of the Tibetan Plateau
}

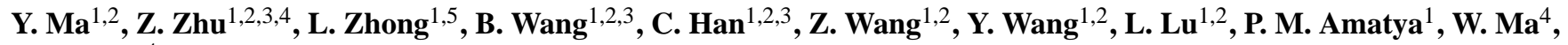 \\ and $\mathbf{Z} \cdot \mathrm{Hu}^{4}$ \\ ${ }^{1}$ Key Laboratory of Tibetan Environment Changes and Land Surface Processes, Institute of Tibetan Plateau Research, \\ Chinese Academy of Sciences, CAS Center for Excellence and Innovation in Tibetan Plateau Earth System Sciences, Beijing \\ 100101, China \\ ${ }^{2}$ Qomolangma Station for Atmospheric Environmental Observation and Research, Chinese Academy of Sciences, Dingri \\ 858200, Tibet, China \\ ${ }^{3}$ University of Chinese Academy of Sciences, Beijing 100049, China \\ ${ }^{4}$ Cold and Arid Regions Environmental and Engineering Research Institute, Chinese Academy of Sciences, \\ Lanzhou 730000, China \\ ${ }^{5}$ School of Earth and Space Sciences, University of Science and Technology of China, Hefei 230026, China \\ Correspondence to: Y. Ma (ymma@itpcas.ac.cn)
}

Received: 5 January 2013 - Published in Atmos. Chem. Phys. Discuss.: 28 March 2013

Revised: 17 December 2013 - Accepted: 9 January 2014 - Published: 11 February 2014

\begin{abstract}
In this study, a parameterization method based on MODIS (Moderate Resolution Imaging Spectroradiometer) data, AVHRR (Advanced Very High-Resolution Radiometer) data and in situ data is introduced and tested for estimating the regional evaporative fraction $\Lambda$ over a heterogeneous landscape. As a case study, the algorithm was applied to the Tibetan Plateau (TP) area. Eight MODIS data images (17 January, 14 April, 23 July and 16 October in 2003; 30 January, 15 April, 1 August and 25 October in 2007) and four AVHRR data images (17 January, 14 April, 23 July and 16 October in 2003) were used in this study to compare winter, spring, summer and autumn values and for annual variation analysis. The results were validated using the "ground truth" measured at Tibetan Observation and Research Platform (TORP) and the CAMP/Tibet (CEOP (Coordinated Enhanced Observing Period) Asia-Australia Monsoon Project (CAMP) on the Tibetan Plateau) meteorological stations. The results show that the estimated evaporative fraction $\Lambda$ in the four different seasons over the TP is in clear accordance with the land surface status. The $\Lambda$ fractions show a wide range due to the strongly contrasting surface features found on the TP. Also, the estimated $\Lambda$ values are in good agreement with "ground truth" measurements, and their absolute percentage difference (APD) is less than $10.0 \%$ at the vali-
\end{abstract}

dation sites. The AVHRR data were also in agreement with the MODIS data, with the latter usually displaying a higher level of accuracy. It was therefore concluded that the proposed algorithm was successful in retrieving the evaporative fraction $\Lambda$ using MODIS, AVHRR and in situ data over the TP. MODIS data are the most accurate and should be used widely in evapotranspiration (ET) research in this region.

\section{Introduction}

As the most prominent and complicated terrain on the earth, the Tibetan Plateau (TP) makes up approximately one quarter of the land area of China, stretching from the Pamir Plateau and Hindu-Kush in the west to the Hengduan Mountains in the east, and from the Kunlun and Qilian mountains in the north to the Himalayas in the south. It has an average elevation over $4000 \mathrm{~m}$ above mean sea level (msl). This region is home to thousands of glaciers in the tropical/subtropical region that exert a direct influence on social and economic development in the regions and countries of China, India, Nepal, Tajikistan, Pakistan, Afghanistan and Bhutan. Due to its topographic character, the plateau surface absorbs a large amount of solar radiation energy, undergoing dramatic 
seasonal changes in surface heat and water fluxes (e.g. Yanai et al., 1992; Ye and Wu, 1998; Hsu and Liu, 2003; Sato and Kimura, 2007). Evapotranspiration (ET) between the land surface and atmosphere of the TP plays an important role in the Asian monsoon system (AMS), which in turn is a major component of the energy and water cycles of the global climate system. Some detailed studies of ET (also known as the latent heat flux) have been reported for different sites and land surface types over the TP in the last few years (e.g. Tanaka et al., 2001; Ma et al., 2005; Li et al., 2006; Zhong et al., 2009). This research, however, was conducted on a point-level or a local-patch-level basis. Remote sensing from satellites offers the possibility to derive ET regional (or areal) distribution over a heterogeneous land surface in combination with data from remote field experimental stations; although regional ET distributions have been reported over the TP in the past decade (e.g. Ma et al., 2003; Zhang et al., 2007; Ma et al., 2009; Liu et al., 2009), the results were only of mesoscale dimensions. To understand the effect of the TP on climate change over China, East Asia, and even globally, the regional distribution of ET distribution of over the whole TP must be determined.

Our objective in this study is to estimate the regional distribution of ET and its seasonal variation over the whole TP with the aid of Moderate Resolution Imaging Spectroradiometer (MODIS), Advanced Very High-Resolution Radiometer (AVHRR) and in situ data. We consider the ET from the surface of the land to be central to understanding climate dynamics and ecosystem productivity (e.g. Churkina et al., 1999); it also has applications in areas such as water resource management. We will introduce "evaporative fraction" $\Lambda$ as an index for ET (after Shuttleworth et al., 1989). $\Lambda$ is defined here as

$\Lambda=\frac{\lambda E}{H+\lambda E}=\frac{\lambda E}{R_{\mathrm{n}}-G_{0}}$,

where $H$ is the sensible heat flux, $\lambda E$ the latent heat flux, $R_{\mathrm{n}}$ the net radiation flux and $G_{0}$ the soil heat flux.

Our goal is not to estimate ET but rather the evaporative fraction $\Lambda$ for the whole TP. This is for two reasons. First, $\Lambda$ is more suitable as an index for surface moisture conditions than ET, because ET itself is a function not only of the land surface conditions (e.g. soil moisture and vegetation) but also of surface available energy $R_{\mathrm{n}}-G_{0}(=H+\lambda E)$. Thus ET cannot be easily interpreted for soil moisture or drought. On the other hand, the evaporative fraction $\Lambda$ can be more directly related to these land surface conditions. Secondly, the evaporative fraction $\Lambda$ is useful for scaling up instantaneous observations to longer time periods. As one knows, a satellite (except for a geostationary satellite) observes each land surface instantaneously at one point during any 1 day. ET, however, can generally change drastically during a day mainly due to changes in sun angle and cloud coverage. Therefore, even if we can accurately estimate ET at the moment of satellite overpass, it cannot be directly related to daily or daytime average ET. In contrast, the evaporative fraction $\Lambda$ is well known to be approximately invariant for a specific area during most of the daytime (e.g. Shuttleworth et al., 1989; Sugita and Brutsaert, 1991; Crago, 1996a, b). Indeed, we found that the evaporative fraction $\Lambda$ remained nearly constant from sunrise to sunset during clear days at the Tibetan Observation and Research Platform stations (TORP, Ma et al., 2008), dependent upon land surface types (see Fig.1 ). The TORP stations used were the BJ Station $\left(31.37^{\circ} \mathrm{N}, 91.90^{\circ} \mathrm{E}\right.$; elevation: $4509 \mathrm{~m}$; land cover: sparse meadow); NAMOR (Nam Co Station for Multisphere Observation and Research, Chinese Academy of Sciences; $30.46^{\circ} \mathrm{N}, 90.59^{\circ} \mathrm{E}$; elevation: $4730 \mathrm{~m}$; land cover: sparse meadow); QOMS (Qomolangma Station for Atmospheric and Environmental Observation and Research, Chinese Academy of Sciences; $28.21^{\circ} \mathrm{N}, 86.56^{\circ} \mathrm{E}$; elevation: $4276 \mathrm{~m}$; land cover: sparse grass - Gobi); and SETS (Southeast Tibet Station for Alpine Environment Observation and Research, Chinese Academy of Sciences; $29.77^{\circ} \mathrm{N}$, $94.73^{\circ} \mathrm{E}$; elevation: $3326 \mathrm{~m}$; land cover: grassland). The values for the evaporative fraction $\Lambda$ in Fig. 1 are derived from sensible heat flux $H$ and latent heat flux $\lambda E$ data measured by eddy correlation at the four stations. They represent averaged diurnal variations over 16 clear days in summertime, 3 days in June, 4 days in July, 5 days in August, and 4 days in September. Therefore, if we estimate daytime average to be $H+\lambda E$ or $R_{\mathrm{n}}-G_{0}$, daytime average ET can be estimated from Eq. (1) by using the instantaneous evaporative fraction $\Lambda$ as derived from satellite imagery. Estimation of the evaporative fraction $\Lambda$ using satellite and in situ data has already been attempted: a similar spatial variation of broadband albedo and surface temperatures was proposed to estimate $\Lambda$ (Su et al., 1999; Roerink et al., 2000). Jiang and Islam (2001) estimated $\Lambda$ by interpolating the PriestleyTaylor parameter. Venturini et al. (2004) compared estimates of $\Lambda$ derived from AVHRR and MODIS sensors over southern Florida, USA. Verstraeten et al. (2005) estimated $\Lambda$ from NOAA imagery at satellite overpass times over European forests. Wang et al. (2006) estimated $\Lambda$ from a combination of day and night land surface temperatures and the Normalized Difference Vegetation Index (NDVI). However, this is the first deliberative study of the evaporative fraction $\Lambda$ over the heterogeneous landscape of the whole TP.

The regional distribution of the evaporative fraction $\Lambda$ over the TP will be both estimated and validated in this study.

\section{Theory and scheme}

The methodology for determining the evaporative fraction $\Lambda$ involves two steps: firstly, determination of the land surface heat fluxes (net radiation flux, soil heat flux, sensible heat flux and latent heat flux) and, secondly, estimation of the evaporative fraction $\Lambda$ by Eq. (1) using the derived sensible heat flux and latent heat flux. The procedure for determining 


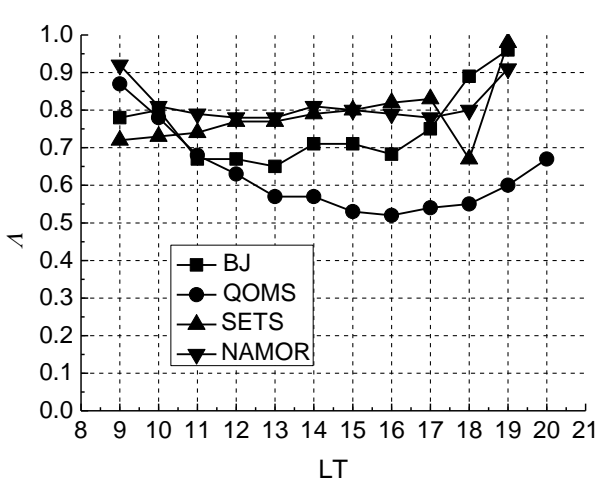

Fig. 1. Diurnal variation of evaporative fraction $(\Lambda)$ at four stations of the Tibetan Plateau. LT is local time, and units are hours.

the land surface heat fluxes has been outlined in the paper of Ma et al. (2011), though it differs from the determination of surface reflectance, surface temperature, surface emissivity, vegetation coverage etc. used in this study. The surface reflectance for short-wave radiation $r_{0}(x, y)$ is retrieved from MODIS data by using Zhong's method (Zhong, 2007) and AVHRR data by employing the model proposed by Ma et al. (2003), which uses land surface and aerological observation data with atmospheric correction. The land surface temperature $T_{\mathrm{sfc}}(x, y)$ is also derived from MODIS data using the method outlined by Zhong et al. (2010) and from AVHRR data following the method of Ma et al. (2003), using land surface and aerological observation data with atmospheric correction. The radiative transfer model MODTRAN (Berk et al., 1989) computes downward short-wave and long-wave radiation at the surface by using satellite data, land surface and aerological observation data combined with atmospheric correction (Ma and Tsukamoto, 2002). With these results obtained, the regional surface net radiation flux $R_{\mathrm{n}}(x, y)$ is determined by using the surface radiation energy budget theorem for land surfaces. The regional soil heat flux $G_{0}(x, y)$ is estimated from $R_{\mathrm{n}}(x, y)$ and field observations over the TP (Ma et al., 2002). The regional sensible heat flux $H(x, y)$ is estimated from $T_{\text {sfc }}(x, y)$, surface and aerological data with the aid of the so-called "tile approach" (Ma et al., 2010). The latter method states that the sensible heat flux $H(x, y)$ will be derived when wind speed $u$, air temperature $T_{\mathrm{a}}$ and specific humidity $q$ at the reference height, zero-plane displacement $d_{0}$, aerodynamic roughness length $z_{0 \mathrm{~m}}$ and thermodynamic roughness length $z_{0 \mathrm{~h}}$, and the excess resistance for heat transportation $k B^{-1}$ have been derived through direct eddy correlation or automatic weather station (AWS) measurements over each tile. In our case study, direct eddy correlation measurements from the TORP stations across the TP (Table 1) were already known. The regional latent heat flux $\lambda E(x, y)$ can be derived as the residual of the energy budget theorem for land surfaces.

If the evaporative fraction $\Lambda$ defining equation (Eq. 1) is adapted to the MODIS and AVHRR pixel scale, it will be- come

$\Lambda(x, y)=\frac{\lambda E(x, y)}{H(x, y)+\lambda E(x, y)}$,

where the $\Lambda$ is between 0.0 and 1.0. $\Lambda$ equaling 0.0 means that the surface is very dry, with no ET from the surface. $\Lambda$ equaling 1.0 means that surface is very wet, with maximum ET from the surface.

\section{Satellite data and field observation data}

Eight swathes of MODIS data (17 January, 14 April, 23 July and 16 October 2003; 30 January, 15 April, 1 August and 25 October 2007) and four swathes of AVHRR data (17 January, 14 April, 23 July and 16 October 2003) were chosen in this study for comparison between winter, spring, summer and autumn. Same day images of AVHRR and MODIS data taken in 2003 (17 January, 14 April, 23 July and 16 October) are used here to find which satellite data are better for the determination of the evaporative fraction $\Lambda$ over the heterogeneous landscape of the TP. Four more images of MODIS data from 2007 are used here for additional method validation as more validation sites were established in 2007 over the TP (Ma et al., 2008).

The most relevant in situ data, collected at the key TORP stations in the TP to support the parameterization of the evaporative fraction $\Lambda$ and analysis of the MODIS and AVHRR images, consist of surface radiation budget components, surface radiation temperatures, surface reflectance, vertical profiles of air temperature, humidity, wind speed and direction measured at atmospheric boundary layer (ABL) towers, wind profiler and RASS, radiosonde and tether sonde, turbulent fluxes measured by eddy-correlation technique, soil heat flux, soil temperature profiles, soil moisture profiles, and the vegetation state (see Table 1). The seven key TORP stations used were the BJ station, NAMOR, QOMS, SETS, and the Haibei, Maqu and Amdo stations (Table 1). The most relevant in situ data, collected at the D105, NPAM and ANNI CAMP/Tibet stations (Ma et al., 2005) over the TP to support the parameterization of the evaporative fraction $\Lambda$ and analysis of MODIS and AVHRR images, consist of surface radiation budget components, surface radiation temperatures, surface reflectance, vertical profiles of air temperature, humidity, AWS-recorded wind speed and direction, soil heat flux, soil temperature profiles, soil moisture profiles, and the vegetation state (see Table 1). The relevant information from these 10 TORP and CAMP/Tibet stations is shown in Table 1.

\section{Cases study and validation}

Figures 2 and 3 show the distribution maps of net radiation flux $R_{\mathrm{n}}$ and evaporative fraction $\Lambda$ over the TP. The distribution maps of net radiation flux are shown here because of their key role in determining the evaporative fraction $\Lambda$. 

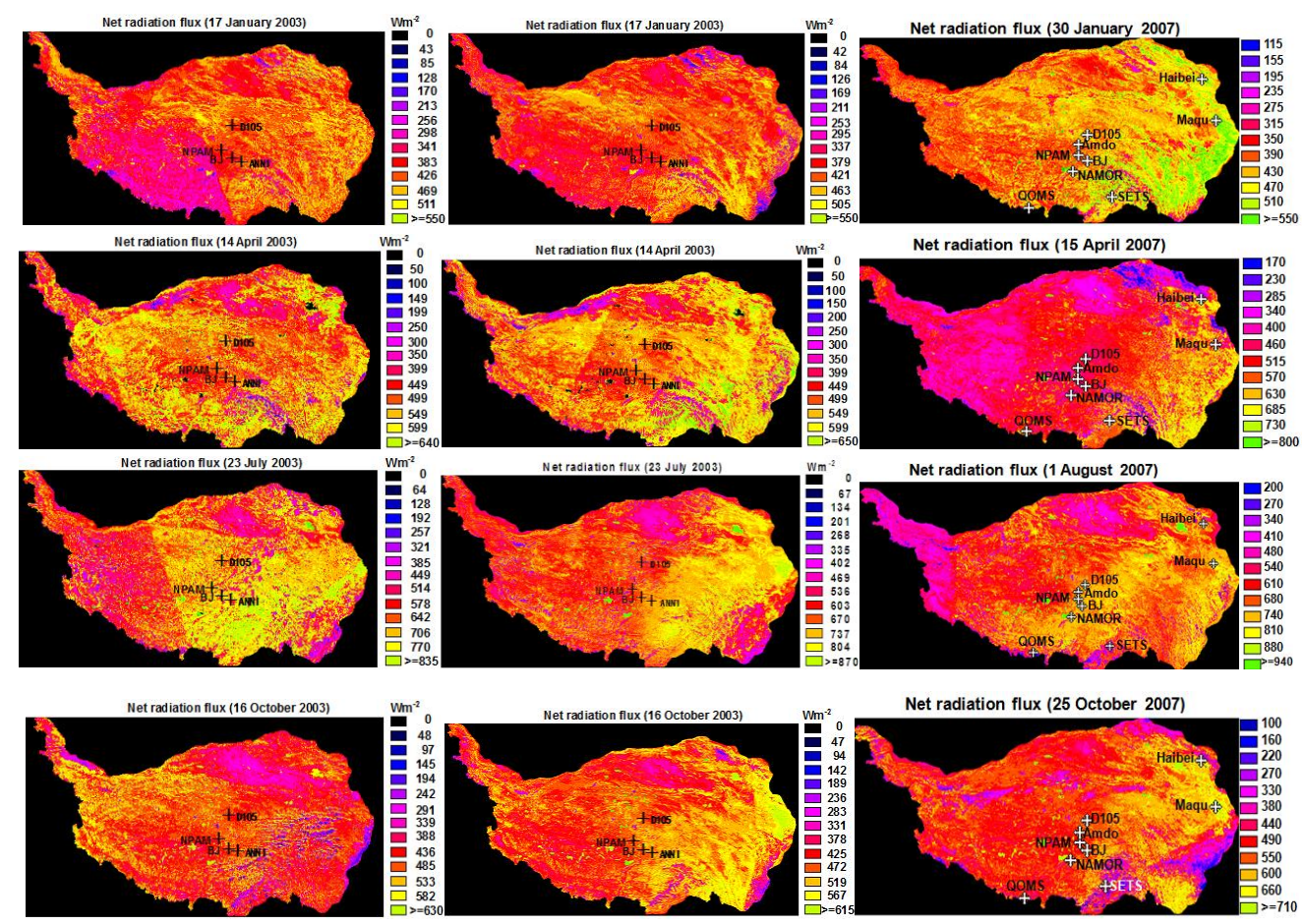

(a)

(b)

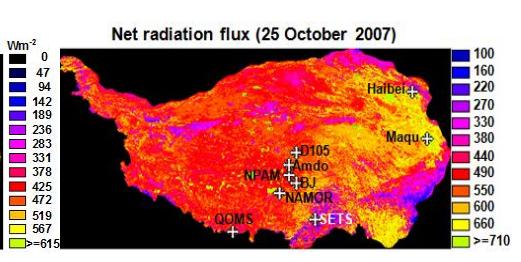

(c)

Fig. 2. The distribution maps of net radiation flux over the Tibetan Plateau area (73.5-107.1 $\left.{ }^{\circ} \mathrm{E}, 25.0-40.1^{\circ} \mathrm{N}\right)$. (a) AVHRR-2003; (b) MODIS-2003; (c) MODIS-2007.
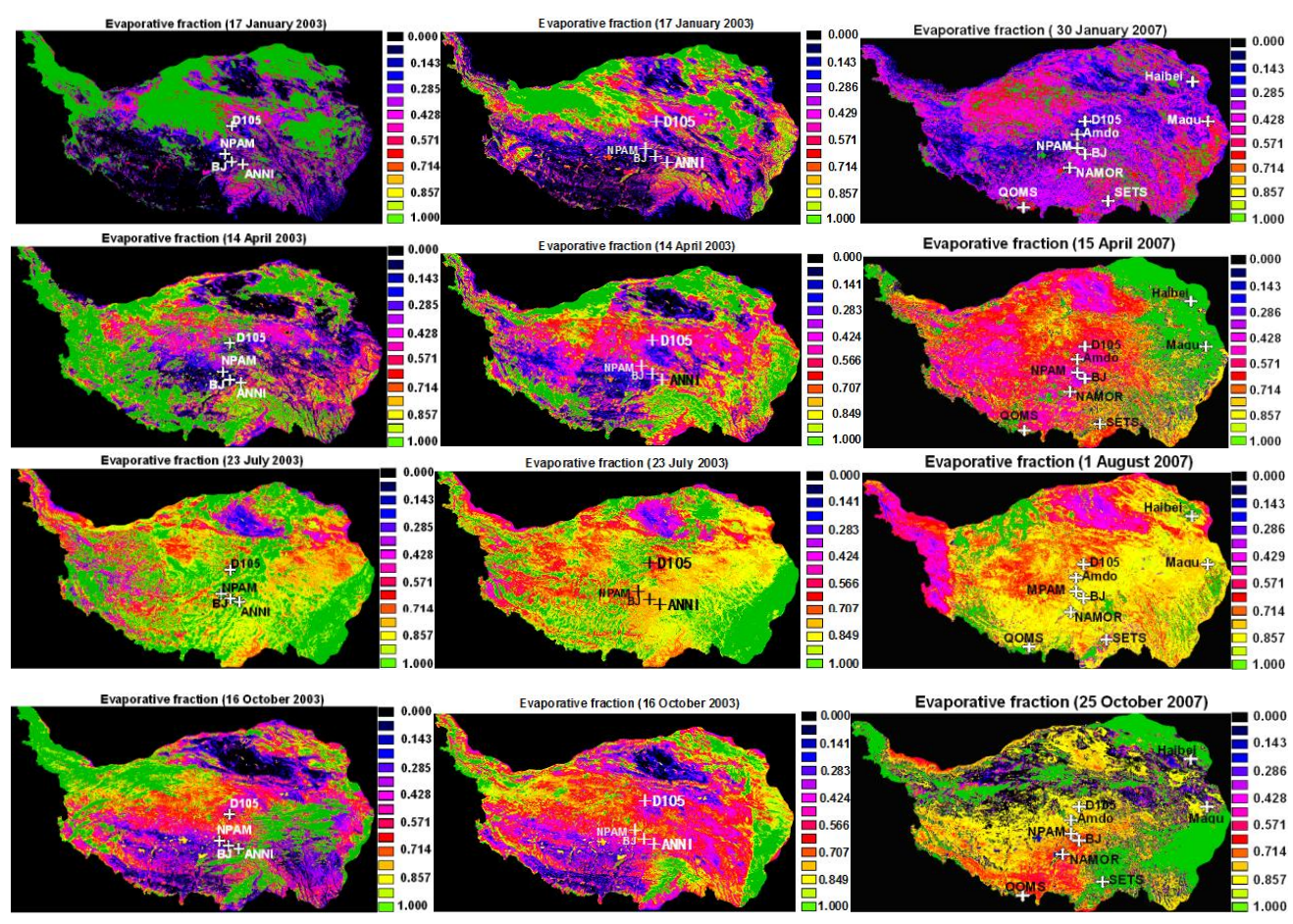

(a)

(b)

(c)

Fig. 3. The distribution maps of evaporative fraction $(\Lambda)$ over the Tibetan Plateau area $\left(73.5-107.1^{\circ} \mathrm{E}, 25.0-40.1^{\circ} \mathrm{N}\right)$. (a) AVHRR-2003; (b) MODIS-2003; (c) MODIS-2007. 
Table 1. The instruments and parameters measured in the seven key stations of TORP and three stations of the CAMP/Tibet.

\begin{tabular}{|c|c|}
\hline Station & Observation item \\
\hline $\begin{array}{l}\text { Seven key stations of TORP: } \\
\text { BJ ( } 31.37^{\circ} \mathrm{N}, 91.90^{\circ} \mathrm{E} \\
\text { elevation: } 4509 \mathrm{~m} \text {; land cover: } \\
\text { sparseness meadow); }\end{array}$ & $\begin{array}{l}20 \mathrm{~m} \text { ABL tower (MILOS520, Vaisala Co.): wind speed, wind direction, } \\
\text { air temperature and humidity (height }(\mathrm{m}): 1.0,2.0,4.0,10.0 \text { and } 20.0) \text {, } \\
\text { surface temperature, soil heat flux (depth }(\mathrm{cm}):-10 \text { and }-20) \text {, air } \\
\text { pressure, rain intensity. }\end{array}$ \\
\hline $\begin{array}{l}\text { NAMOR }\left(30.46^{\circ} \mathrm{N}, 90.59^{\circ} \mathrm{E}\right. \\
\text { elevation: } 4730 \mathrm{~m} \text {; land cover: } \\
\text { sparseness meadow); } \\
\text { QOMS }\left(28.21^{\circ} \mathrm{N}, 86.56^{\circ} \mathrm{E} \text {; }\right. \\
\text { elevation: } 4276 \mathrm{~m} \text {; land cover: } \\
\text { sparse grass - Gobi); }\end{array}$ & $\begin{array}{l}\text { Radiation measurement system (CNR-1, Kipp \& Zonen Co.): } \\
\text { short-wave radiation (downward and upward), long-wave radiation } \\
\text { (downward and upward). } \\
\text { Soil moisture and soil temperature measurement system (SMTMS): soil } \\
\text { moisture (Trime EZ, Imko Co.) (depth (cm): }-10,-20,-40,-80 \text {, } \\
-160) \text {; soil temperature (Pt100, Datamark Co.) (depth (cm): }-10,-20 \text {, } \\
-40,-80,-160) \text {. }\end{array}$ \\
\hline $\begin{array}{l}\text { SETS }\left(29.77^{\circ} \mathrm{N}, 94.73^{\circ} \mathrm{E}\right. \\
\text { elevation: } 3326 \mathrm{~m} \text {; land cover: } \\
\text { grass land); } \\
\text { Haibei }\left(37.62^{\circ} \mathrm{N}, 101.30^{\circ} \mathrm{E} \text {; }\right. \\
\text { elevation: } 3220 \mathrm{~m} \text {; land cover: } \\
\text { grassy marshland); }\end{array}$ & $\begin{array}{l}\text { GPS radio-sonde system (MW21 DigiCORA III, Vaisala Co.): pro- } \\
\text { file of air pressure, air temperature, relative humidity, wind speed and } \\
\text { direction. (This system is only set up in QOMS and BJ.) } \\
\text { Wind profiler and RASS (LAP3000,Vaisala Co.): profile of air } \\
\text { temperature, wind speed and direction. (This system is only set up in } \\
\text { QOMS, BJ and Maqu.) }\end{array}$ \\
\hline $\begin{array}{l}\text { Maqu }\left(33.89^{\circ} \mathrm{N}, 102.14^{\circ} \mathrm{E} \text {; }\right. \\
\text { elevation: } 3423 \mathrm{~m} \text {; land cover: } \\
\text { grassy marshland) } \\
\text { Amdo }\left(32.14^{\circ} \mathrm{N}, 91.37^{\circ} \mathrm{E} \text {; }\right. \\
\text { elevation: } 4695 \mathrm{~m} \text {; land cover: } \\
\text { grassy marshland) }\end{array}$ & $\begin{array}{l}\text { Sonic turbulent measurement system (CSAT3, Campbell Co.) and } \\
\mathrm{CO}_{2} / \mathrm{H}_{2} \mathrm{O} \text { flux measurement system (LI7500, Campbell Co.): wind } \\
\text { speed, wind direction, air temperature, relative humidity, the } \\
\text { characteristic length scales of surface layer, sensible heat flux, latent } \\
\text { heat flux, } \mathrm{CO}_{2} / \mathrm{H}_{2} \mathrm{O} \text { flux, stability parameter. }\end{array}$ \\
\hline $\begin{array}{l}\text { Three stations of the } \\
\text { CAMP/Tibet: } \\
\text { D105 ( } 33.06^{\circ} \mathrm{N}, 91.94^{\circ} \mathrm{E} \text {; } \\
\text { elevation: } 5039 \mathrm{~m} \text {; land cover: } \\
\text { sparseness meadow), }\end{array}$ & $\begin{array}{l}10 \mathrm{~m} \text { automatic weather station (AWS) (MILOS520, Vaisala Co.): wind } \\
\text { speed, wind direction, air temperature and humidity }(1.0 \mathrm{~m}, 5 \mathrm{~m}, 10 \mathrm{~m} \text { ), } \\
\text { surface temperature, soil heat flux (depth (cm):-10 and }-20) \text {, air } \\
\text { pressure, rain intensity, and snow depth. }\end{array}$ \\
\hline $\begin{array}{l}\text { NPAM }\left(31.93^{\circ} \mathrm{N}, 91.71^{\circ} \mathrm{E}\right. \\
\text { elevation: } 4620 \mathrm{~m} \text {; land cover: } \\
\text { grassy marshland) and }\end{array}$ & $\begin{array}{l}\text { Radiation measurement system (CNR-1, Kipp \& Zonen Co.): } \\
\text { short-wave radiation (downward and upward), long-wave radiation } \\
\text { (downward and upward). }\end{array}$ \\
\hline $\begin{array}{l}\text { ANNI }\left(31.25^{\circ} \mathrm{N}, 92.17^{\circ} \mathrm{E}\right. \\
\text { elevation: } 4480 \mathrm{~m} \text {; land cover: } \\
\text { grassy marshland) }\end{array}$ & $\begin{array}{l}\text { Soil moisture and soil temperature measurement system (SMTMS): soil } \\
\text { moisture (Trime EZ, Imko Co.) (depth (cm): }-10,-20,-40,-80 \text {, } \\
-160) \text {; soil temperature (Pt100, Datamark Co.) (depth }(\mathrm{cm}):-10,-20 \text {, } \\
-40,-80,-160) \text {. }\end{array}$ \\
\hline
\end{tabular}

The $R_{\mathrm{n}}$ and $\Lambda$ distribution maps are based on $2875 \times 1487$ pixels with a size of approximately $1 \times 1 \mathrm{~km}^{2}$. The estimated $R_{\mathrm{n}}$ and $\Lambda$ values can be validated by field measurements. In situ data observed in the seven key TORP stations at Haibei, Maqu, Amdo, BJ, NAMOR, QOMS and SETS (Table 1) and the two CAMP/Tibet stations at D105 and NPAM (Ma et al., 2008) are used for the 2007 validation; four CAMP/Tibet stations at D105, NPAM, ANNI and BJ (Ma et al., 2005) are used for the 2003 validation. In Fig. 4 and Tables 2-4, estimated results are validated against the values measured in the stations. The absolute percentage difference (APD) quantitatively measures the difference between the estimated results $\left(V_{\text {derived }(i)}\right)$ and measured values $\left(V_{\operatorname{measured}(i)}\right)$ :

$\mathrm{APD}=\frac{\left|V_{\text {derived }(i)}-V_{\text {measured }(i)}\right|}{V_{\text {measured }(i)}}$.
The results show the following: (1) the estimated net radiation $R_{\mathrm{n}}$ and evaporative fraction $\Lambda$ in four different months over the TP are in good accordance with the land surface status. The TP includes a variety of land surfaces such as large areas of grassy marshland, grassland areas exhibiting some desertification, sparse grass - Gobi, sparse meadow, many small rivers and lakes, snowy mountains (some with glaciers), forest, farmland etc. These estimated parameters therefore show a wide range due to the TP's strongly contrasting surface features. (2) The estimated pixel values (Fig. 3) of the evaporative fraction $\Lambda$ in summer (1 August 2007 and 23 July 2003) and autumn (25 October 2007 and 16 October 2003) are higher than in winter (30 January 2007 and 17 January 2003) and spring (15 April 2007 and 14 April 2003). The evaporative fraction $\Lambda$ in the summer is mostly 
from 0.70 to 1.0 , mostly ca. 0.60 in autumn, mostly ca. 0.50 in spring, and mostly ca. 0.30 in winter (some of the $\Lambda$ values are 1.0 in the distribution maps, indicating cloud coverage). The seemingly substantial differences between the 2003 and 2007 images are explained by day-to-day variability, indicating that ET values in the summer and autumn in the TP are much higher than in the winter and spring. The reason for this is that most of the land surface is wet and covered by green grass and growing vegetation in the summer and autumn; during the winter and spring on the TP it is dry and most mountain ranges are covered by snow and ice. In other words, sensible heat and latent heat fluxes play different roles in the partition of the net radiation flux in different months in the TP: sensible heat flux plays the main role in the winter and spring, and latent heat flux plays the main role in the summer and autumn. (3) The mean evaporative fraction $\Lambda$ values derived from MODIS data over the TP area increase from January to April and again to August, then decrease from October (Fig. $3 \mathrm{~b}$ and c). The $\Lambda$ values are $0.275,0.415,0.567$ and 0.406 for 2007 and $0.271,0.342,0.569$ and 0.347 for 2003. The mean evaporative fraction $\Lambda$ values derived from AVHRR data over the TP also increase from January to April and again to July, decreasing from October. These values are 0.267, 0.335, 0.502, and 0.331 (Fig. 3a). (4) Because land surface cover properties are very complex in spring (April) (ice, snow, seasonal and long-term permafrost, grassland and lakes are all identified in this month), the evaporative fraction $\Lambda$ distribution for this month is also complicated (Fig. 3). (5) Most estimated regional evaporative fraction $\Lambda$ values with APD less than $10.0 \%$ from validation sites in the TP are in good agreement with field measurements, except for evaporative fraction $\Lambda$ values estimated from MODIS data at the NAMOR station (APD $=12.9 \%$ ) on 1 August 2007 (Fig. 4, Tables 2-4). The reason for this is that the radiation transportation processes were considered in more detail, not only using the MODTRAN model, land surface and aerological data and the ABL process, but also employing the "tile approach" for measuring and calculating accurately the wind speed $u$, air temperature $T_{\mathrm{a}}$ and specific humidity $q$ at the reference height, zero-plane displacement $d_{0}$, aerodynamic roughness length $z_{0 \mathrm{~m}}$ and thermodynamic roughness length $z_{0 \mathrm{~h}}$, and the excess resistance for heat transportation $k B^{-1}$ for each tile (Ma et al., 2011). We would suggest, therefore, that our proposed parameterization algorithm for the evaporative fraction $\Lambda$ is reasonable, and can be used over the TP. (6) The retrieved evaporative fraction $\Lambda$ and net radiation $R_{\mathrm{n}}$ values derived from MODIS data are superior to those from AVHRR data even when the same methods are used (Figs. 24; Tables 2 and 3). It means that the estimated values from MODIS data are closer to the "ground truth" measured at the validation stations (Fig. 4, Tables 2 and 3). There may be many reasons for this, such as the image quality itself, the different split window algorithms (SWAs), or the different algorithms for water vapour. It is therefore concluded that the MODIS data provide the more accurate values and should be

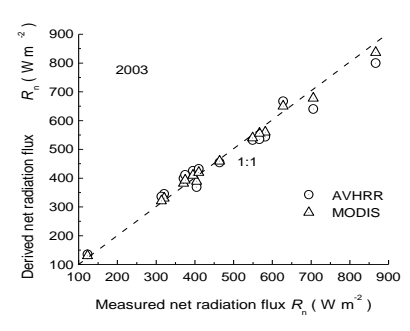

(a)

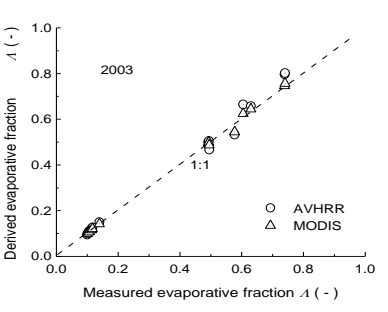

(c)

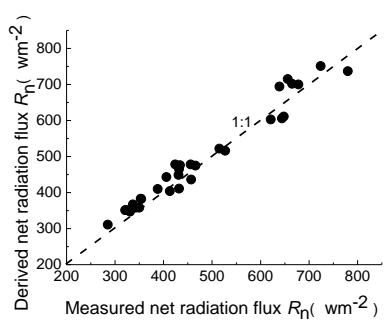

(b)

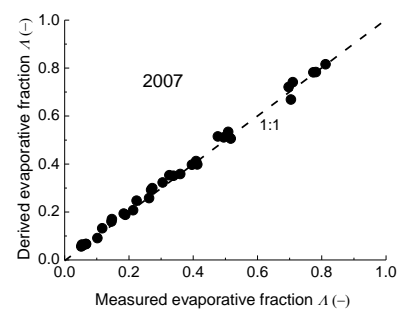

(d)
Fig. 4. Comparison between the derived net radiation flux $\left(R_{\mathrm{n}}\right)$, evaporative fraction $(\Lambda)$, and the field measurement values, together with a $1: 1$ line in 2003 and 2007.

used widely for the determination of surface heat fluxes and ET over the TP.

\section{Concluding remarks}

In this study, regional distributions of the evaporative fraction $\Lambda$ over the heterogeneous landscape of the TP are estimated with the aid of MODIS data, AVHRR data and in situ data. The MODIS data are more reliable than AVHRR data for estimating the evaporative fraction $\Lambda$ over a heterogeneous landscape. Compared with field measurements, the proposed evaporative fraction $\Lambda$ has been proven to be a more accurate index for generating related ET values over a heterogeneous landscape.

Regionalizing the ET over a heterogeneous landscape is not straightforward. The parameterization methodology presented in this research is still in its developmental stage as evinced by the fact that only a single set of values at a specific time on a specific day is used in this research. To obtain more accurate regional ET values and seasonal and annual variations in ET over the TP, more field observations, more accurate radiation transfer models for determining surface reflectance and surface temperatures, more MODIS data, and more data from other satellites such as the Advanced Space borne Thermal Emission and Reflection Radiometer (ASTER), Landsat-5 TM, Landsat-7 ETM, Geo-stationary Meteorological Satellite (GMS), and Along Track Scanning Radiometer (ATSR) have to be used. This is our next step. 
Table 2. Comparison of the derived net radiation flux from AVHRR ( $\left.\mathrm{Cal}_{\mathrm{AVHRR}}\right)$ and MODIS (Cal $\left.{ }_{\mathrm{MODIS}}\right)$ vs. the values measured (Meas.) at the Tibetan Plateau with absolute percent difference (APD) in 2003.

\begin{tabular}{|c|c|c|c|c|c|c|c|c|c|c|}
\hline \multirow[b]{2}{*}{ Sites } & \multicolumn{5}{|c|}{ January 2003} & \multicolumn{5}{|c|}{14 April 2003} \\
\hline & $\mathrm{Cal}_{\mathrm{AVHRR}}$ & $\mathrm{Cal}_{\text {MODIS }}$ & Meas. & $\mathrm{APD}_{\mathrm{AVHRR}}$ & APD $_{\text {MODIS }}$ & $\mathrm{Cal}_{\mathrm{AVHRR}}$ & $\mathrm{Cal}_{\text {MODIS }}$ & Meas. & $\mathrm{APD}_{\mathrm{AVHRR}}$ & APD $_{\text {MODIS }}$ \\
\hline D105 & 369 & 374 & 381 & $3.1 \%$ & $1.8 \%$ & 399 & 387 & 371 & $7.6 \%$ & $4.3 \%$ \\
\hline NPAM & 414 & 436 & 446 & $7.2 \%$ & $2.2 \%$ & 544 & 568 & 582 & $6.5 \%$ & $2.4 \%$ \\
\hline ANNI & 412 & 417 & 424 & $2.8 \%$ & $1.7 \%$ & 532 & 540 & 549 & $3.1 \%$ & $1.6 \%$ \\
\hline \multirow[t]{2}{*}{ BJ } & 384 & 390 & 398 & $3.5 \%$ & $2.0 \%$ & 432 & 421 & 410 & $5.4 \%$ & $2.7 \%$ \\
\hline & \multicolumn{5}{|c|}{23 July 2003} & \multicolumn{5}{|c|}{16 October 2003} \\
\hline Sites & $\mathrm{Cal}_{\text {AVHRR }}$ & $\mathrm{Cal}_{\text {MODIS }}$ & Meas. & APD $_{\text {AVHRR }}$ & APD MODIS & $\mathrm{Cal}_{\mathrm{AVHRR}}$ & $\mathrm{Cal}_{\text {MODIS }}$ & Meas. & $\mathrm{APD}_{\mathrm{AVHRR}}$ & APD $_{\text {MODIS }}$ \\
\hline D105 & 628 & 607 & 589 & $6.6 \%$ & $3.1 \%$ & 411 & 390 & 375 & $9.6 \%$ & $4.0 \%$ \\
\hline NPAM & 758 & 750 & 742 & $2.2 \%$ & $1.1 \%$ & 454 & 460 & 464 & $2.8 \%$ & $0.9 \%$ \\
\hline ANNI & 704 & 685 & 666 & $5.7 \%$ & $2.9 \%$ & 535 & 558 & 567 & $5.6 \%$ & $1.6 \%$ \\
\hline BJ & 577 & 561 & 544 & $6.1 \%$ & $3.1 \%$ & 336 & 320 & 314 & $7.0 \%$ & $1.9 \%$ \\
\hline
\end{tabular}

Table 3. Comparison of the derived evaporative fraction $\Lambda$ from AVHRR (Cal ${ }_{\mathrm{AVHRR}}$ ) and MODIS (Cal $\mathrm{MODIS}$ ) vs. the values measured (Meas.) at the Tibetan Plateau with absolute percent difference (APD) in 2003.

\begin{tabular}{|c|c|c|c|c|c|c|c|c|c|c|}
\hline \multirow[b]{2}{*}{ Sites } & \multicolumn{5}{|c|}{ January 2003} & \multicolumn{5}{|c|}{14 April 2003} \\
\hline & $\mathrm{Cal}_{\mathrm{AVHRR}}$ & $\mathrm{Cal}_{\text {MODIS }}$ & Meas. & $\mathrm{APD}_{\mathrm{AVHRR}}$ & $\mathrm{APD}_{\text {MODIS }}$ & $\mathrm{Cal}_{\mathrm{AVHRR}}$ & $\mathrm{Cal}_{\text {MODIS }}$ & Meas. & $\mathrm{APD}_{\mathrm{AVHRR}}$ & $\mathrm{APD}_{\text {MODIS }}$ \\
\hline D105 & 0.110 & 0.109 & 0.108 & $1.9 \%$ & $0.9 \%$ & 0.110 & 0.107 & 0.106 & $3.8 \%$ & $0.9 \%$ \\
\hline NPAM & 0.095 & 0.100 & 0.100 & $5.0 \%$ & $0.0 \%$ & 0.150 & 0.142 & 0.139 & $7.9 \%$ & $2.2 \%$ \\
\hline ANNI & 0.100 & 0.101 & 0.101 & $1.0 \%$ & $0.0 \%$ & 0.120 & 0.116 & 0.114 & $5.3 \%$ & $1.8 \%$ \\
\hline \multirow[t]{2}{*}{ BJ } & 0.225 & 0.223 & 0.220 & $2.3 \%$ & $1.4 \%$ & 0.126 & 0.121 & 0.117 & $7.7 \%$ & $3.4 \%$ \\
\hline & \multicolumn{5}{|c|}{23 July 2003} & \multicolumn{5}{|c|}{16 October 2003} \\
\hline Sites & $\mathrm{Cal}_{\mathrm{AVHRR}}$ & Cal.MODIS & Meas. & $\mathrm{APD}_{\mathrm{AVHRR}}$ & $\mathrm{APD}_{\text {MODIS }}$ & $\mathrm{Cal}_{\mathrm{AVHRR}}$ & $\mathrm{Cal}_{\text {MODIS }}$ & Meas. & $\mathrm{APD}_{\mathrm{AVHRR}}$ & APD $_{\text {MODIS }}$ \\
\hline D105 & 0.665 & 0.625 & 0.605 & $9.9 \%$ & $3.3 \%$ & 0.499 & 0.496 & 0.492 & $1.4 \%$ & $0.8 \%$ \\
\hline NPAM & 0.796 & 0.747 & 0.739 & $7.7 \%$ & $1.1 \%$ & 0.505 & 0.500 & 0.494 & $2.2 \%$ & $1.2 \%$ \\
\hline ANNI & 0.802 & 0.757 & 0.740 & $8.4 \%$ & $2.3 \%$ & 0.533 & 0.545 & 0.577 & $7.6 \%$ & $5.5 \%$ \\
\hline BJ & 0.657 & 0.645 & 0.630 & $4.3 \%$ & $2.3 \%$ & 0.467 & 0.487 & 0.495 & $5.7 \%$ & $1.6 \%$ \\
\hline
\end{tabular}

Table 4. Comparison of the derived net radiation flux $R_{\mathrm{n}}$ and evaporative fraction $\Lambda$ (Cal.) vs. the values measured (Meas.) at the Tibetan Plateau with absolute percent difference (APD) in 2007.

\begin{tabular}{|c|c|c|c|c|c|c|c|c|c|c|c|c|}
\hline \multicolumn{2}{|l|}{ January: } & \multicolumn{2}{|c|}{$R_{\mathrm{n}}\left(\mathrm{Wm}^{-2}\right)$} & \multicolumn{3}{|c|}{$\Lambda(-)$} & \multirow{2}{*}{$\frac{\text { April: }}{\text { Cal. }}$} & \multicolumn{2}{|c|}{$R_{\mathrm{n}}\left(\mathrm{Wm}^{-2}\right)$} & \multicolumn{3}{|c|}{$\Lambda(-)$} \\
\hline Sites & Cal. & Meas. & APD & Cal. & Meas. & APD & & Meas. & APD & Cal. & Meas. & APD \\
\hline Haibei & 347 & 331 & $4.8 \%$ & 0.412 & 0.409 & $0.7 \%$ & 603 & 621 & $2.9 \%$ & 0.398 & 0.413 & $3.6 \%$ \\
\hline Maqu & 383 & 353 & $8.5 \%$ & 0.188 & 0.188 & $0.0 \%$ & 449 & 431 & $4.2 \%$ & 0.434 & 0.409 & $6.1 \%$ \\
\hline D105 & 351 & 321 & $9.3 \%$ & 0.066 & 0.066 & $0.0 \%$ & 352 & 323 & $9.0 \%$ & 0.351 & 0.339 & $3.5 \%$ \\
\hline Amdo & 382 & 354 & $7.9 \%$ & 0.056 & 0.052 & $0.1 \%$ & 410 & 388 & $5.7 \%$ & 0.322 & 0.305 & $5.6 \%$ \\
\hline NPAM & 404 & 413 & $2.2 \%$ & 0.083 & 0.085 & $2.4 \%$ & 606 & 644 & $5.9 \%$ & 0.247 & 0.224 & $10.0 \%$ \\
\hline BJ & 311 & 285 & $9.1 \%$ & 0.055 & 0.056 & $1.8 \%$ & 441 & 432 & $2.1 \%$ & 0.258 & 0.263 & $1.9 \%$ \\
\hline NAMOR & 358 & 343 & $4.4 \%$ & 0.059 & 0.056 & $5.3 \%$ & 522 & 515 & $1.4 \%$ & 0.506 & 0.517 & $2.1 \%$ \\
\hline QOMS & 367 & 337 & $8.9 \%$ & 0.174 & 0.173 & $0.1 \%$ & 475 & 466 & $1.9 \%$ & 0.207 & 0.213 & $2.8 \%$ \\
\hline SETS & 436 & 457 & $4.6 \%$ & 0.066 & 0.067 & $1.5 \%$ & 611 & 648 & $5.7 \%$ & 0.510 & 0.495 & $3.1 \%$ \\
\hline \multicolumn{2}{|l|}{ August: } & \multicolumn{2}{|c|}{$R_{\mathrm{n}}\left(\mathrm{Wm}^{-2}\right)$} & \multicolumn{3}{|c|}{$\Lambda(-)$} & October: & \multicolumn{2}{|c|}{$R_{\mathrm{n}}\left(\mathrm{Wm}^{-2}\right)$} & \multicolumn{3}{|c|}{$\Lambda(-)$} \\
\hline Sites & Cal. & Meas. & APD & Cal. & Meas. & APD & Cal. & Meas. & APD & Cal. & Meas. & APD \\
\hline Haibei & 358 & 350 & $2.3 \%$ & 0.699 & 0.704 & $0.7 \%$ & 478 & 456 & $4.8 \%$ & 0.292 & 0.269 & $8.6 \%$ \\
\hline Maqu & 694 & 639 & $8.6 \%$ & 0.799 & - & - & 476 & 434 & $9.7 \%$ & 0.515 & 0.477 & $8.0 \%$ \\
\hline D105 & 633 & - & - & 0.667 & - & - & 465 & 432 & $7.6 \%$ & 0.193 & 0.184 & $4.9 \%$ \\
\hline Amdo & 686 & - & - & 0.711 & - & - & 475 & - & - & 0.396 & 0.396 & $0.0 \%$ \\
\hline NPAM & 737 & 780 & $5.5 \%$ & 0.924 & 0.897 & $3.0 \%$ & 516 & 527 & $2.1 \%$ & 0.299 & 0.273 & $9.6 \%$ \\
\hline BJ & 702 & 665 & $5.6 \%$ & 0.721 & 0.697 & $3.5 \%$ & 443 & 406 & $9.1 \%$ & 0.132 & 0.135 & $1.9 \%$ \\
\hline NAMOR & 715 & 656 & $9.0 \%$ & 0.681 & 0.782 & $12.9 \%$ & 479 & - & - & 0.358 & 0.360 & $0.4 \%$ \\
\hline QOMS & 700 & 678 & $3.2 \%$ & 0.740 & 0.710 & $4.2 \%$ & 448 & 424 & $4.7 \%$ & 0.159 & 0.146 & $9.2 \%$ \\
\hline SETS & 751 & 724 & $3.7 \%$ & 0.815 & 0.811 & $0.5 \%$ & 472 & - & - & 0.533 & 0.509 & $4.8 \%$ \\
\hline
\end{tabular}


Acknowledgements. This work was under the auspices of the Chinese National Key Programme for Developing Basic Sciences (2010CB951701), the Chinese Academy of Sciences (XDB03030201), the CMA Special Fund for Scientific Research in the Public Interest (GYHY201406001), the National Natural Foundation of China (91337212, 4127501041275028 and 41375009), and EU-FP7 projects of CORE-CLIMAX (313085). The in situ data of Haibei station and Maqu station came from Y. Li, X. Zhao and Y. Zhang.

Edited by: Q. Fu

\section{References}

Berk, A., Bernstein, L. S., and Robertson D. C.: MODTRAN: a moderate resolution model for LOTRAN 7, GL-TR-89-0122, Air Force Geophys. Lab., Hanscom AFB, MA, 38 pp., 1989.

Churkina, G., Running, S. W., Schloss, A. L., and the Participants of the Potsdam NPP Model Inter-comparison: Comparing global models of terrestrial net primary productivity (NPP): the importance of water availability, Glob. Change Biol., 5, 46-55, 1999.

Crago, R. D.: Comparison of the evaporative fraction and the Priestley-Taylor a for parameterizing daytime evaporation, Water Resour. Res., 32, 1403-1409, 1996a.

Crago, R. D.: Conservation and variability of the evaporative fraction during the daytime, J. Hydrol., 180, 173-194, 1996b.

Hsu, H. and Liu, X.: Relationship between the Tibetan Plateau heating and East Asian summer monsoon rainfall, Geophys. Res. Lett., 30, D2066, doi:10.1029/2003GL017909, 2003.

Jiang, L. and Islam, S.: Estimation of surface evaporation map over Southern Great Plains using remote sensing data, Water Resour. Res., 37, 329-340, 2001.

Li, M., Ma, Y., Ma, W., Hu, Z., Ishikawa, H., Su, Z., and Sun, F.: Analysis of turbulence characteristics over the northern Tibetan Plateau area, Adv. Atmos. Sci., 23, 579-585, 2006.

Liu, J., Wang, S., Yu, S., Yang, D., and Zhang, L.: Climate warming and growth of high-elevation inland lakes on the Tibetan Plateau, Global Planet. Change, 67, 209-217, 2009.

Ma, Weiqiang, Ma, Yaoming, Li, Maoshan, Hu, Zeyong, Zhong, Lei, Su, Zhongbo, Ishikawa, Hirohiko, and Wang, Jiemin: Estimating surface fluxes over the north Tibetan Plateau area with ASTER imagery, Hydrol. Earth Syst. Sci., 13, 57-67, doi:10.5194/hess-13-57-2009, 2009.

Ma, Y., and Tsukamoto, O.: Combining satellite remote sensing with field observations for land surface heat fluxes over inhomogeneous landscape, China Meteorological Press, Beijing, China, 2002.

Ma, Y., Su, Z., Li, Z.-L., Koike, T., and Menenti, M.: Determination of regional net radiation and soil heat flux densities over heterogeneous landscape of the Tibetan Plateau, Hydrol. Process., 16, 2963-2971, 2002.

Ma, Y., Ishikawa, H., Menenti, M., Su, Z., Yao, T., Koike, T., and Yasynari, T.: Regionalization of surface fluxes over heterogeneous landscape of the Tibetan Plateau by using satellite remote sensing, J. Meteorol. Soc. Jpn., 81, 277-293, 2003.

Ma, Y., Fan, S., Ishikawa, H., Tsukamoto, O., and Yao, T.: Diurnal and inter-monthly variation of land surface heat fluxes over the central Tibetan Plateau area, Theor. Appl. Climatol., 80, 259$273,2005$.
Ma, Y., Kang, S., Zhu, L., Xu, B., Tian, L., and Yao, T.: Tibetan Observation and Research Platform-Atmosphere-land interaction over a heterogeneous landscape, B. Am. Meteorol. Soc., 89, 1487-1492, 2008.

Ma, Y., Menenti, M., and Feddes, R.: Parameterization of heat fluxes at heterogeneous surfaces by integrating satellite measurements with surface layer and atmospheric boundary layer observations, Adv. Atmos. Sci., 27, 328-336, 2010.

Ma, Y., Zhong, L., Wang, B., Ma, W., Chen, X., and Li, M.: Determination of land surface heat fluxes over heterogeneous landscape of the Tibetan Plateau by using the MODIS and in situ data, Atmos. Chem. Phys., 11, 10461-10469, doi:10.5194/acp11-10461-2011, 2011.

Roerink, G. J., Su, Z., and Menenti, M.: S-SEBI: A simple remote sensing algorithm to estimate the surface energy balance, Phys. Chem. Earth Pt B, 25, 147-157, 2000.

Sato, T. and Kimura, F.: How does the Tibetan Plateau affect the transition of Indian monsoon rainfall?, Mon. Weather Rev., 135, 2006-2015, 2007.

Shuttleworth, W. J., Gurney, R. J., Hsu, A. Y., and Ormsby, J. P.: FIFE: the variation in energy partition at surface flux sites, IAHSAISH P., 186, 67-74, 1989.

Su, Z., Pelgrum, H., and Menenti, M.: Aggregation effects of surface heterogeneity in land surface processes, Hydrol. Earth Syst. Sci., 3, 549-563, doi:10.5194/hess-3-549-1999, 1999.

Sugita, M. and Brutsaert, W.: Daily evaporation over a region from lower boundary-layer profiles measured with radiosondes, Water Resour. Res., 27, 747-752, 1991.

Tanaka, K., Ishikawa, H., Hayashi, T., Tamagawa, I., and Ma, Y.: Surface Energy Budget at Amdo on Tibetan Plateau using GAME/Tibet IOP'98 Data, J. Meteorol. Soc. Jpn., 79, 505-517, 2001.

Venturini, V., Bisht, G., Islam, S., and Jiang, L.: Comparison of evaporative fractions estimated from AVHRR and MODIS sensors over South Florida, Remote Sens. Environ., 93, 77-86, 2004.

Verstraeten, W. W., Veroustraete, F., and Feyen, J.: Estimating evapotranspiration of European forests from NOAA-imagery at satellite overpass time: Towards an operational processing chain for integrated optical and thermal sensor data products, Remote Sens. Environ., 96, 256-276, 2005.

Wang, K., Li, Z., and Cribb, M.: Estimation of evaporative fraction from a combination of day and night land surface temperatures and NDVI: A new method to determine the Priestley-Taylor parameter, Remote Sens. Environ., 102, 293-305, 2006.

Yanai, M., Li, C., and Song, Z.: Seasonal heating of the Tibetan Plateau and its effects on the evolution of the Asian summer monsoon, J. Meteorol. Soc. Jpn., 70, 319-351, 1992.

Ye, D. and Wu, G.: The role of the heat source of the Tibetan Plateau in the general circulation, Meteorol. Atmos. Phys., 67, 181-198, 1998.

Zhang, J., Yao, F., Zheng, L., and Yang, L.: Evaluation of grassland dynamics in the Northern-Tibet Plateau of China using remote sensing and climate data, Sensors, 7, 3312-3328, 2007.

Zhong, L.: Measurement and satellite remote sensing of land surface characteristic parameters over the Tibetan Plateau area, $\mathrm{PhD}$ Thesis, Graduate University of Chinese Academy of Sciences, 124 pp., 2007.

Zhong, L., Ma, Y., Su, Z., Lu, L., Ma, W., and Lu, Y.: Land-atmosphere energy transfer and surface boundary layer 
characteristics in the Rongbu Valley on the northern slope of Mt. Everest, Arct. Antarct. Alp. Res., 41, 396-405, 2009.
Zhong, L., Ma, Y., Salama Suhyb, Mhd., and Su, Z.: Assessment of vegetation dynamics and their response to variations in precipitation and temperature in the Tibetan Plateau, Clim. Change, 103, 519-535, doi:10.1007/s10584-009-9787-8, 2010. 